\title{
Dark Rearing Alters the Development of GABAergic Transmission in Visual Cortex
}

\author{
Bernardo Morales, Se-Young Choi, and Alfredo Kirkwood \\ Mind Brain Institute, Johns Hopkins University, Baltimore, Maryland 21218
}

We studied the role of sensory experience in the maturation of GABAergic circuits in the rat visual cortex. Between the time at which the eyes first open and the end of the critical period for experience-dependent plasticity, the total GABAergic input converging into layer II/III pyramidal cells increases threefold. We propose that this increase reflects changes in the number of quanta released by presynaptic axons. Here, we show that the developmental increase in GABAergic input is prevented in animals deprived of light since birth but not in animals deprived of light after a period of normal experience. Thus, sensory experience appears to play a permissive role in the maturation of intracortical GABAergic circuits.

Key words: synaptic inhibition; critical period; IPSC; EPSC; plasticity; sensory experience
Sensory experience during the postnatal critical period is essential for the normal maturation of visual cortical circuits and function (Hubel and Wiesel, 1962). Although many studies have been devoted to the modification of excitatory circuits (Beaver et al., 1999; Rittenhouse et al., 1999; Di Cristo et al., 2001), there are indications that GABAergic circuits also change (Winfield, 1983). Indeed, one hypothesis is that the maturation of inhibitory circuits plays an important role in timing the critical period for the modifications of excitatory connections (Komatsu, 1983; Kirkwood and Bear, 1994; Hensch et al., 1998; Huang et al., 1999).

Evidence for the slow cortical maturation of inhibitory mechanisms derives primarily from anatomical studies. In rodents, the numbers of inhibitory synapses (Blue and Parnavelas, 1983; Miller, 1986) and levels of GABA-synthesizing enzymes increase postnatally until week 5 of age (Huang et al., 1999), which is close to puberty for these animals. The role of visual experience in this process has remained elusive. Although recordings in vivo suggest a weakened synaptic inhibition in animals deprived of light since birth (Benevento et al., 1992), the anatomical data are inconclusive. Perhaps this is because different approaches have been used to target different aspects of inhibitory function. For example, visual deprivation from birth reportedly decreases GABA immunoreactivity (Benevento et al., 1996; Gordon et al., 1997) and GABAergic synapses (Gabbott and Stewart, 1987) but does not affect the levels of GABA-synthesizing enzymes (Mower and Guo, 2001).

Direct intracellular analyses of the maturation of intracortical inhibition have focused primarily on aspects of the $\mathrm{GABA}_{\mathrm{A}}$ response that change before the eyes open, such as the shift in reversal potential (Agmon et al., 1996; Owens et al., 1999) and the increase in the response kinetics associated with changes in

\footnotetext{
Received March 8, 2002; revised June 17, 2002; accepted July 3, 2002.

This work was supported by National Institutes of Health Grants R01-EY12124-03 and P50-MH58880-01. We thank Dr. H. K. Lee, D. Bergles, D. Linden, and S. Hsiao for valuable comments on this manuscript.

Correspondence should be addressed to Alfredo Kirkwood, Mind Brain Institute, Johns Hopkins University, 338 Krieger Hall, 3400 North Charles Street, Baltimore, MD 21218. E-mail: kirkwood@jhu.edu.

B. Morales' present address: Facultad de Quimica y Biología, Departamento de Ciencias Biológicas, Universidad de Santiago, Santiago, 40 Correo 33 Chile.

Copyright (ㄷ) 2002 Society for Neuroscience $0270-6474 / 02 / 228084-07 \$ 15.00 / 0$
}

$\mathrm{GABA}_{\mathrm{A}}$ receptor subunit composition (Dunning et al., 1999). Thus, although inhibitory responses can be evoked in most cortical cells by postnatal week 3 (Luhmann and Prince, 1991; Komatsu and Iwakiri, 1993), very little is known about the changes that might take place beyond that age. The aim of this study was to understand the changes in the maturation of inhibitory circuits that might mediate the timing of the critical period. We report that in the time between when the eyes open ( 2 weeks) and the end of the critical period (5 weeks), the total GABAergic input converging into pyramidal cells undergoes a threefold increase. Furthermore, the enhancement of inhibition requires visual experience and involves an increase in the number of release sites per individual input.

\section{MATERIALS AND METHODS}

Coronal slices $(300 \mu \mathrm{m})$ of visual cortex from 2- to 8-week-old rats were prepared as described previously (Kirkwood and Bear, 1994). Briefly, after sectioning in ice-cold oxygenated $\left(95 \% \mathrm{O}_{2} / 5 \% \mathrm{CO}_{2}\right)$ dissection buffer (in mm: 212.7 sucrose, $5 \mathrm{KCl}, 1.25 \mathrm{NaH}_{2} \mathrm{PO}_{4}, 3 \mathrm{MgCl}_{2}, 1 \mathrm{CaCl}_{2}$, $26 \mathrm{NaHCO}_{3}, 10$ dextrose, and 10 kynurenate), slices were transferred to a storage chamber containing recording buffer for at least $1 \mathrm{hr}$ before recording. In the recording buffer, sucrose is replaced by $124 \mathrm{mM} \mathrm{NaCl}$, $\mathrm{MgCl}_{2}$ is lowered to $1 \mathrm{~mm}, \mathrm{CaCl}_{2}$ is raised to $2 \mathrm{~mm}$, and kynurenate is omitted.

Whole-cell voltage clamp in visually identified layer II/III pyramidal cells was performed using an Axopatch 1D (Axon Instruments, Foster City, CA) and a Warner Instruments (Hamden, CT) PC-505A amplifier. Patch pipettes (2-4 M $\Omega$ ) were filled with (in $\mathrm{mM}$ ): 130 Cs-gluconate, 8 $\mathrm{KCl}, 10$ EGTA, $10 \mathrm{HEPES}$, and 10 lidocaine $N$-ethyl bromide at a $\mathrm{pH}$ of 7.4 and 275-285 mOsm. In some experiments (see Figs. 5 and 6), $130 \mathrm{~mm}$ Cs-gluconate was replaced by $140 \mathrm{~mm} \mathrm{CsCl}$. The junction potential (typically $<5 \mathrm{mV}$ ) was compensated. Only cells with membrane potentials more negative than $-65 \mathrm{mV}$, access resistance $<20 \mathrm{M} \Omega(8-18 \mathrm{M} \Omega$, compensated at $80 \%)$, and input resistance $>100 \mathrm{M} \Omega(130-410 \mathrm{M} \Omega)$ were studied. The cells were discarded if the input or the access resistance changed $>15 \%$. All recordings were done at $28-30^{\circ} \mathrm{C}$.

Synaptic responses were evoked with $0.2 \mathrm{msec}$ current pulses delivered with a bipolar stimulating electrode $(200 \mu \mathrm{m}$ diameter; FHC, Bowdoinham, ME) placed in the middle of the cortical thickness (approximately the boundary of layers V and IV). Interstimulus intervals were $>10 \mathrm{sec}$ to minimize depression resulting from high-frequency stimulation. Compound IPSCs were recorded at $0 \mathrm{mV}$, and EPSCs were recorded at -60 $\mathrm{mV}$, the reversal potential of the IPSC (see Fig. 4). This value $(-60 \mathrm{mV}$ ) is more positive than the predicted Nernst potential of $\mathrm{Cl}^{-}$because of the non-negligible permeability to gluconate of the $\mathrm{GABA}_{\mathrm{A}}$ channels (Barker and Harrison, 1988). In some experiments (described in Figures 
A
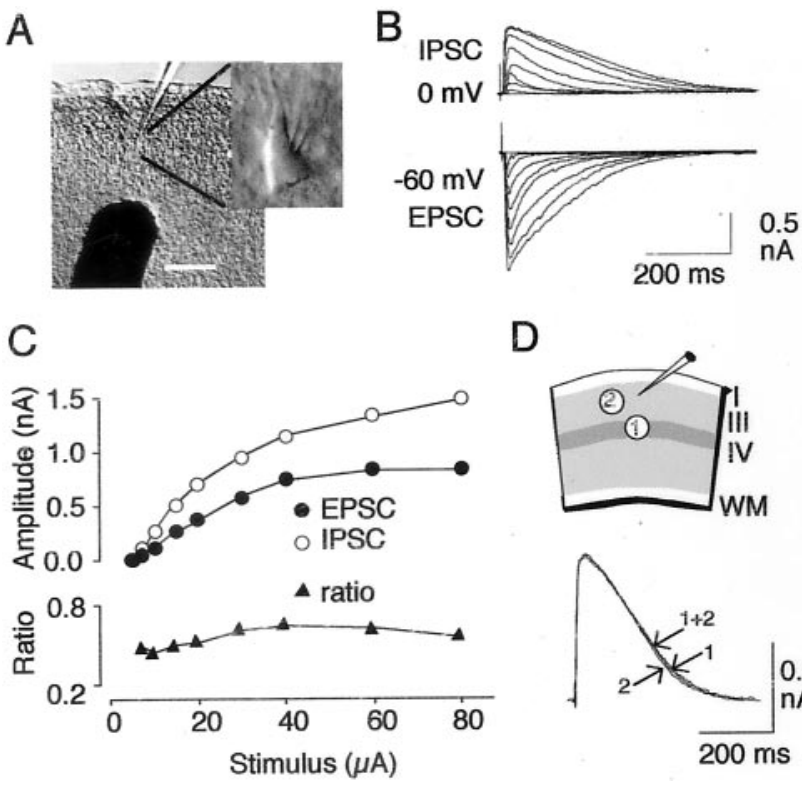

D
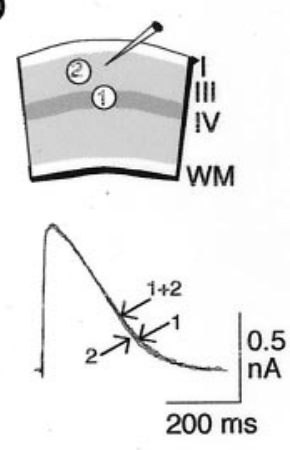

Figure 1. Determination of the maximal IPSCs in layer II/III cells. $A$, Stimulus recording configuration. Scale bar, $200 \mu \mathrm{m}$. B, C, Examples of IPSCs and EPSCs evoked by a stimulus series of increasing intensity. Both the IPSCs and the IPSC/EPSC reached saturation at a stimulus intensity of $40 \mu \mathrm{A}$. $D$, Saturation of the IPSCs does not depend on the stimulation site. Top, Stimulus recording configuration. Bottom, Maximal IPSCs evoked by the indicated stimulating electrode. $W M$, White matter.

1 through 4$)$, the stimulus intensity was varied systematically $(5,7.5,15,20$, $40,60$, and $80 \mu \mathrm{A})$. At least four to six responses at each intensity were averaged to compute the EPSC and IPSC. Responses were digitized at 10 $\mathrm{kHz}$ and analyzed using IGOR (WaveMetrics Inc., Lake Oswego, OR). Spontaneous miniature IPSCs (mIPSCs) were recorded in the presence of (in $\mu \mathrm{M}$ ): 1 tetrodotoxin (TTX), 100 2-amino-5-phosphonovaleric acid (APV), and 20 6-cyano-7-nitroquinoxaline-2,3-dione (CNQX) and analyzed with the Mini Analysis program (Synaptosoft, Decatur, GA). We considered all recorded events in a single experiment for the determination of rates (between 800 and 3000) but excluded "bursts" with highly superimposed events in the determination of amplitudes. The decay constant, conversely, was calculated using the average of the first 100 isolated events. In all cases, the data were fitted with a single exponential. Minimal stimulation experiments were done using the same "regular" electrode placed in layer IV, which gave results similar to those using smaller glass pipettes closer to the target cell. Two major criteria for acceptance were a single latency of the response and a sharp threshold (Gil et al., 1999). Seventy to 300 responses were recorded in these experiments. Statistical significance was assessed using $t$ tests or two-way repeated-measures ANOVAs followed by the Student-Newman-Keuls post hoc test. CNQX, APV, and bicuculline methiodide (BMI) were purchased from Sigma/RBI (St. Louis, MO).

\section{RESULTS}

We investigated how age and experience regulate the strength of synaptic inhibition in layer II/III of the rat visual cortex using the magnitude of the maximal IPSC to quantify the total inhibitory input converging onto a given cell (Ling and Benardo, 1998, 1999). As shown in Figure 1, the amplitude of IPSCs evoked with layer IV stimulation saturates as the stimulus intensity is increased. The IPSC/EPSC ratio also saturates, and its maximal value is used to compare the balance of inhibition and excitation between different cells. To confirm that stimulation of layer IV recruited nearly all of the fibers capable of evoking measurable responses in layer II/III cells, we placed an additional stimulating electrode $\sim 100 \mu \mathrm{m}$ lateral to the recorded cells. Stimulation of either pathway or both of them together evoked comparable
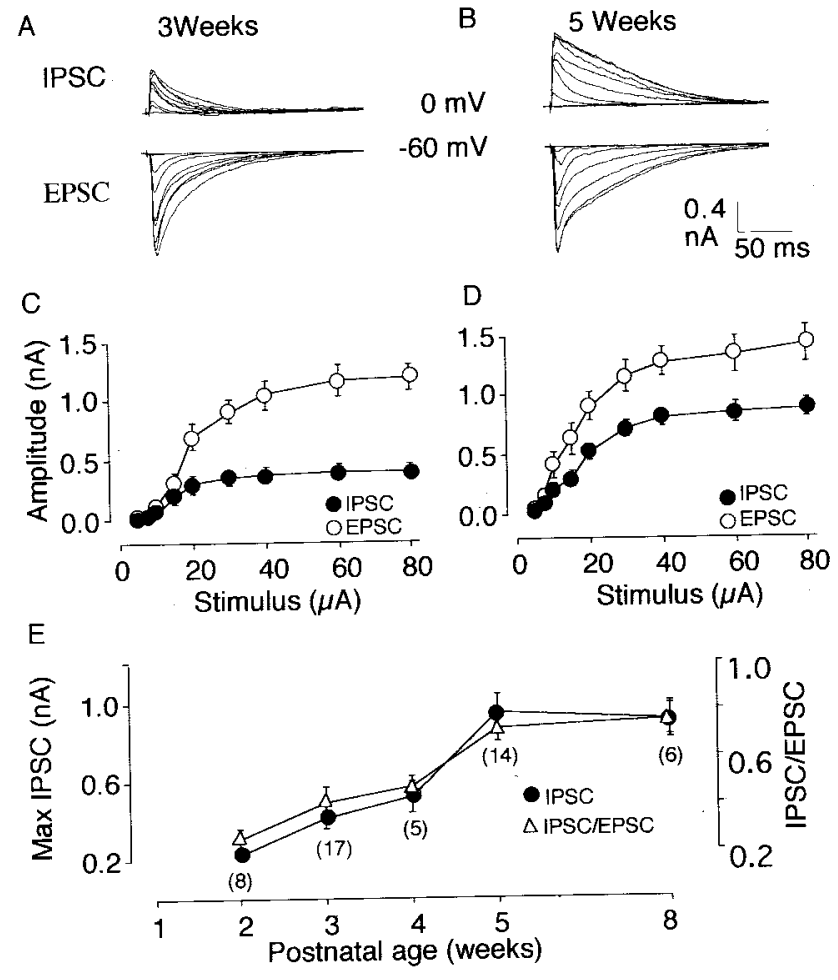

Figure 2. Developmental changes in the balance of excitation and inhibition. $A, B$, Examples of responses evoked by a stimulus series of increasing intensity in a cell from a 3 -week-old rat $(A)$ and a 5 -week-old rat $(B)$. The input-output relationship for the IPSC (solid symbols) and EPSC (open symbols) is shown in $C$ for 3 -week-old rats and in $D$ for 5 -week-old rats. $E$, Developmental changes in the maximal IPSC (solid symbols) and in the IPSC/EPSC ratio (open symbols). The number of cells included in each data point is given in parentheses.

maximal IPSCs $(n=3)$, indicating that the maximal IPSC is an adequate measure of the total inhibitory input converging in layer II/III cells.

\section{Developmental changes in magnitude of the maximal IPSC}

It has been proposed that changes in the strength of synaptic inhibition set the timing of the critical period for experiencedependent plasticity (Komatsu, 1983; Kirkwood and Bear, 1994; Hensch et al., 1998; Huang et al., 1999), which in rodents peaks at 3 weeks and ends by week 5 (Maffei et al., 1992; Fagiolini et al., 1994). Therefore, we decided to investigate how the magnitude of the maximal IPSC changes at 3 and 5 weeks of age. As shown in Figure 2, the magnitude of the maximal IPSC nearly doubled in this period [from $420 \pm 55 \mathrm{pA}(n=17)$ at 3 weeks to $955 \pm 58$ pA $(n=14)$ at 5 weeks] and plateaued thereafter. The magnitude of the EPSC at the saturating intensity barely changed during this period. As a result, the balance of inhibition/excitation was dramatically altered during the first postnatal weeks (Fig. 2C). These developmental changes in the potency of synaptic inhibition mirror the decline of plasticity observed in the rat visual cortex.

\section{Effects of sensory experience on the potency of inhibitory inputs}

Many aspects of the functional maturation of the visual cortex can be delayed by sensory deprivation (Fagiolini et al., 1994). To examine the role of visual experience in the development of synaptic inhibition, we studied the maximal IPSC in 5-week-old 
A

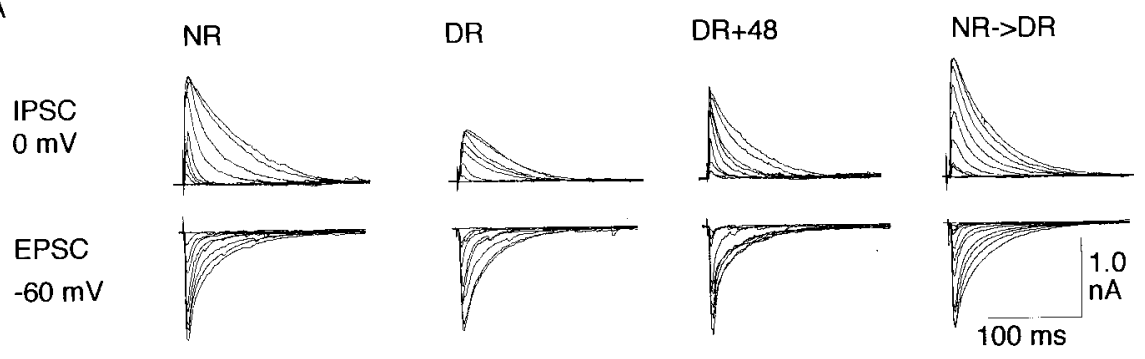

Figure 3. Visual experience triggers the developmental increase in the maximal IPSC. $A$, Traces are examples of responses evoked by stimulus series of increasing intensity in cells from rats reared in the indicated conditions. $B$, Average magnitude of the maximal IPSC, EPSC, and IPSC/EPSC ratio from rats reared in the indicated conditions. Asterisks denote values significantly different $(p<0.005)$ from controls. $N R$, Normally reared; $D R$, dark reared; $D R+48$, dark reared plus 2 d normally reared; $N R \rightarrow D R / N R D R$, normally reared-dark reared.

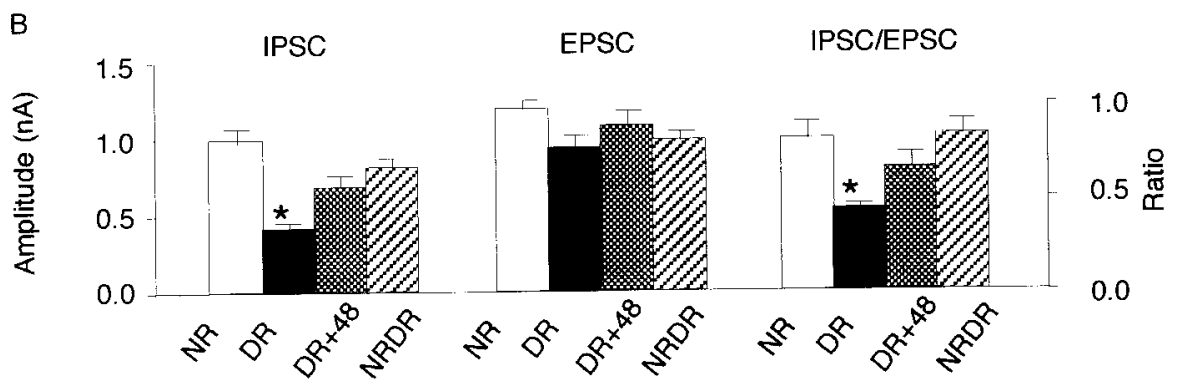

rats reared under different conditions. One group of animals was reared in normal light/dark cycles ( 5 week normally reared rats: 7 rats, 15 cells), and another group was reared in complete darkness (5 week dark-reared rats: 6 rats, 16 cells). In addition, some dark-reared animals were exposed to light for $2 \mathrm{~d}$ before the experiments ( 5 week dark-reared +48 rats: 5 rats, 10 cells). A third group was reared normally for 3 weeks and subsequently placed in the dark for the remaining 2 weeks [normally reareddark reared (5 week normally reared $\rightarrow$ dark reared): 8 rats, 17 cells]).

The results, summarized in Figure 3, indicate that sensory experience affects the development of synaptic inhibition profoundly. The maximal IPSC was reduced by nearly half in darkreared cells (462 $\pm 43 \mathrm{pA}$ ) compared with normally reared cells $(939 \pm 90 \mathrm{pA})$. The reduction in the IPSC magnitude was substantially reversed after $2 \mathrm{~d}$ of exposure to light (5 week normally reared $\rightarrow$ dark reared, $778.6 \pm 55.6 \mathrm{pA})$. In contrast, 2 weeks of sensory deprivation after normal rearing ( 5 week normally reared $\rightarrow$ dark reared) did not affect the maximal IPSC $(804 \pm 75 \mathrm{pA})$. The results from a two-way ANOVA indicated that these differences were significant $\left(F_{(3,71)}=10.05 ; p<0.001\right)$, and a Student-Newman-Keuls post hoc test confirmed that the IPSC was significantly smaller in dark-reared cells $(p<0.001)$. The EPSC, on the other hand, was affected less by the rearing conditions. Although the maximal EPSC was somewhat smaller in dark-reared cells $(980 \pm 71 \mathrm{pA})$ compared with the other groups (normally reared, $1197 \pm 76 \mathrm{pA} ; 5$ week dark reared $+48,1137 \pm$ $81 \mathrm{pA}$; 5 week normally reared $\rightarrow$ dark reared, $1009 \pm 69 \mathrm{pA})$, the differences did not reach statistical significance $\left(F_{(3,71)}=1.87\right.$; $p=0.1430)$. Finally, as expected, the IPSC/EPSC ratio was significantly reduced $\left(F_{(3,71)}=6.143 ; p=0.009\right)$ in dark-reared cells $(0.471 \pm 0.027)$ compared with the other groups (normally reared, $0.789 \pm 0.071 ; 5$ week dark reared $+48,0.729 \pm 0.058 ; 5$ week normally reared $\rightarrow$ dark reared, $0.818 \pm 0.091)$. To confirm the effects of sensory experience, we compared IPSCs and EPSCs from cells recorded from dark-reared and normally reared animals in a blinded study. The maximal IPSC was significantly ( $p=$ $0.04)$ smaller in 5 week dark-reared $(643 \pm 163 \mathrm{pA} ; n=8)$ than in 5 week normally reared $(1280 \pm 152 \mathrm{pA} ; n=8)$ animals. The IPSC/EPSC ratio was also smaller $(0.52 \pm 0.11$ in 5 week dark reared; $0.95 \pm 0.10$ in 5 week normally reared; $p<0.001)$.
Together, the results support the idea that sensory experience is necessary to trigger the maturation of GABAergic circuits in the cortex.

To test the possibility that the age- and experience-related changes observed in the IPSCs were simply a result of rearrangements of polysynaptic connections, we studied monosynaptic IPSCs isolated by applying $100 \mu \mathrm{M}$ APV and $20 \mu \mathrm{M}$ CNQX in a bath (Fig. 4). Under these conditions, the maximal IPSCs were still significantly larger $\left(F_{(2,21)}=10.14 ; p=0.0008\right)$ in 5 week normally reared cells $(730 \pm 60 \mathrm{pA}$; four rats, seven cells) than in 3 week normally reared cells ( $321 \pm 13$; five rats, seven cells) or 5 week dark-reared cells (432 \pm 32 pA; five rats, 10 cells). Similarly, the peak conductance underlying the maximal IPSC, estimated from a linear fit of the $I-V$ plots shown in Figure $4 C$, was also larger in 5 week normally reared cells $(11.09 \pm 0.253 \mathrm{nS}$; $n=5$ and 9) than in 3 week normally reared cells $(5.89 \pm 0.147$ $\mathrm{nS} ; n=3$ and 5$)$ or 5 week dark-reared cells $(7.73 \pm 0.217 \mathrm{nS} ; n=$ 3 and 6). In contrast, age or experience did not significantly affect the passive properties of the cells, such as the input resistance $[347 \pm 27 \mathrm{M} \Omega(n=21)$ in 3 week normally reared cells, $348 \pm 23$ $\mathrm{M} \Omega(n=21)$ in 5 week normally reared cells, and $361 \pm 19 \mathrm{M} \Omega$ $(n=20)$ in 5 week dark-reared cells] or capacitance $(80 \pm 7,79$ \pm 0.7 , and $75 \pm 7 \mathrm{pF}$ in 3 week normally reared, 5 week normally reared, and 5 week dark-reared cells, respectively). These results confirm that age and experience directly affect the magnitude of the evoked IPSCs.

\section{Effects of age and sensory deprivation on unitary IPSCs}

Changes in the maximal IPSC may result from several factors, including the number of inhibitory inputs, the number of release sites at each input, the magnitude of the unitary response, and the probability of release. To explore the latter possibility, we studied paired-pulse depression (PPD) evoked with a $20 \mathrm{msec}$ interval. The magnitude of PPD, computed as the ratio of the second response to the first, is commonly used to assess changes in the probability of release. We found that this ratio increases with age, from $0.49 \pm 0.04$ at 3 weeks $(n=12)$ to $0.87 \pm 0.07$ at 5 weeks $(n=20)$. Furthermore, dark rearing $(0.57 \pm 0.03)$ prevents this increase. These differences in PPD were significant $\left(F_{(2,44)}=\right.$ 13.288; $p<0.0001)$ and are consistent with the hypothesis that 

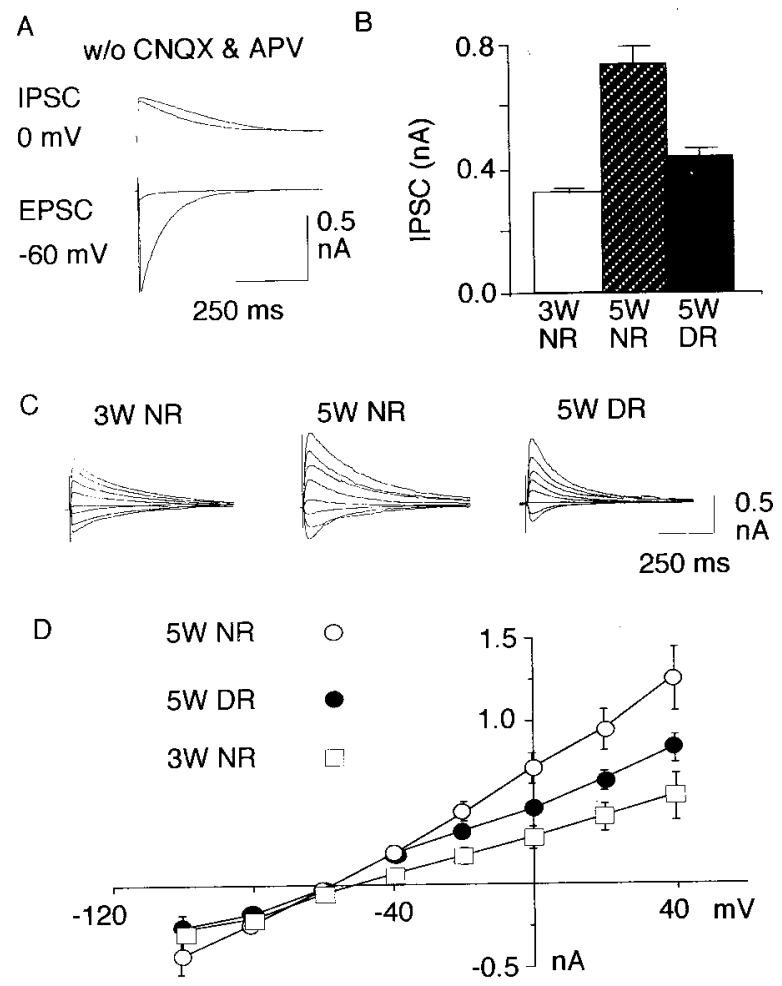

Figure 4. Effects of age and experience on the maximal monosynaptic IPSC. $A$, A $20 \mu \mathrm{M}$ concentration of CNQX and a $100 \mu \mathrm{M}$ concentration of APV abolish the responses recorded at $-60 \mathrm{mV}$ but barely affect the responses recorded at $0 \mathrm{mV}$. $B$, Average amplitude of monosynaptic maximal IPSCs recorded in 3-week-old $(3 W)$ cells, 5 -week-old $(5 W)$ cells, and dark-reared $(D R)$ cells. $C, D, I-V$ relationship for the maximal IPSCs. $C$, Examples of IPSC recorded at different membrane potentials in 3-week-old cells, 5-week-old cells, and dark-reared cells. $D, I-V$ plot of the peak amplitude of the maximal IPSCs. NR, Normally reared.

there is a higher probability of release in cells from young and dark-reared rats. Hence, changes in the probability of release are unlikely to account for the regulation of the maximal IPSC.

To investigate a possible regulation of the magnitude of the unitary responses, we studied the release of spontaneous mIPSCs in cells from 3- and 5-week-old normal-reared rats and 5-week-old dark-reared rats (see Materials and Methods). The recordings were done at $-80 \mathrm{mV}$ because sustained postsynaptic depolarization might reduce the release of GABA from presynaptic terminals (Pitler and Alger, 1992; Wilson and Nicoll, 2001). To facilitate the detection of mIPSCs at this potential, the recording pipette contained the same $\left[\mathrm{Cl}^{-}\right]$as the external buffer. Under those conditions, the mIPSCs reversed at $0 \mathrm{mV}$ (Fig. $5 A)(n=3)$ and were reversibly abolished by $1 \mu \mathrm{M}$ BMI (Fig. $5 B)(n=3)$. To minimize biases introduced by dendritic filtering of events originating far away from the soma, we adopted the standard criterion of analyzing only those cases in which the rise time did not show a negative correlation with the amplitude of the events (Fig. 5C).

Figure 6 summarizes the results obtained in cells prepared from 3-week-old rats $(n=19)$ and 5-week-old rats reared normally $(n=15)$ or in the dark $(n=16)$. The decay kinetics of the mIPSCs (Fig. 6A), which in all cases was fitted with a single exponential, was similar in the three groups $\left(F_{(2,47)}=0.163 ; p=\right.$ $0.85)$. The average decay constant (see Materials and Methods) was $10.3 \pm 0.7 \mathrm{msec}$ in 3 week normally reared cells, $9.7 \pm 0.8$ $\mathrm{msec}$ in 5 week normally reared cells, and $10.2 \pm 0.9 \mathrm{msec}$ in 5
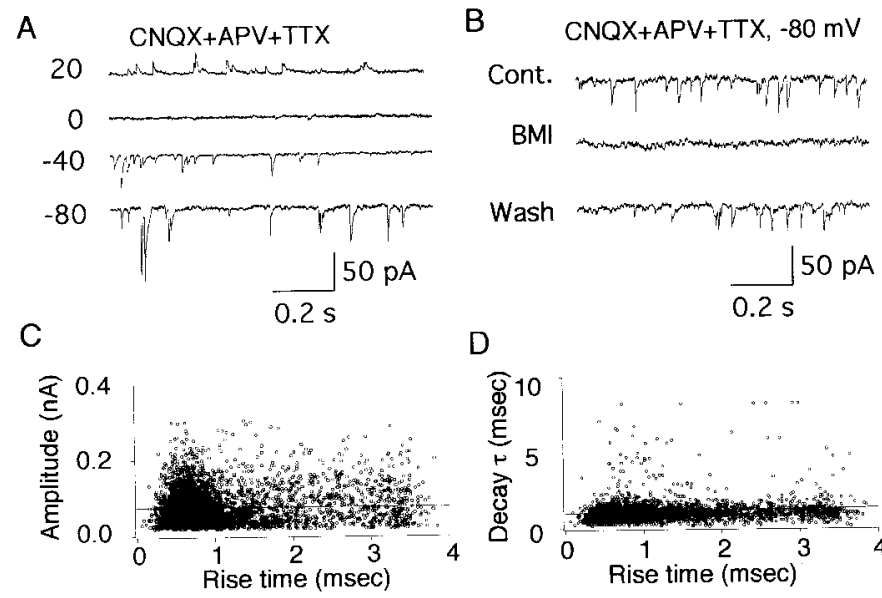

Figure 5. Miniature IPSCs recorded in $20 \mu \mathrm{M}$ CNQX, $100 \mu \mathrm{M}$ APV, and $1 \mu \mathrm{M}$ TTX in layer II/III cells. $A$, Reversal potential of mIPSCs. The current traces were recorded at the indicated holding potential. $B$, A 1.0 $\mu \mathrm{M}$ concentration of BMI reversibly eliminates mIPSCs. $C$, $D$, Examples showing the relationship between the $10-90 \%$ rise time and the amplitude $(C)$ and the decay $(D)$ for all of the mIPSCs recorded in a 5-weekold cell. The solid lines indicate the best linear fit of the data.

week dark-reared cells. This similarity is intriguing, considering the twofold developmental decrease in decay constant (from 43 to $17 \mathrm{msec}$ ) that has been reported in cells grown in culture (Dunning et al., 1999). The discrepancy might reflect a slower maturation in cultured cells. Under similar experimental conditions, the decay constant has decreased to $11 \mathrm{msec}$ in slices from 21-d-old animals yet it is still $35 \mathrm{msec}$ in 23-d-old cultured cells (Dunning et al., 1999).

The average mIPSC amplitude (Fig. $6 C$ ) was significantly different among the three groups $\left(F_{(2,47)}=3.916 ; p=0.023\right)$. However, unlike the maximal compound IPSCs, the largest $\mathrm{mIPSCs}$ were recorded in 5 week dark-reared cells $(53.3 \pm 4.1$ $\mathrm{pA}$ ), and there was no effect of age on the amplitude of mIPSCs $(38.7 \pm 3.4 \mathrm{pA}$ in 3 week normally reared cells; $40 \pm 4.4 \mathrm{pA}$ in 5 week normally reared cells). In contrast, the mIPSC frequency (Fig. 6D) showed an age-dependent increase (from $10.3 \pm 0.7 \mathrm{~Hz}$ in 3 week normally reared cells to $17.0 \pm 2.4 \mathrm{~Hz}$ in 5 week normally reared cells) that was reduced by dark rearing (10.2 \pm $0.9 \mathrm{~Hz}$ in 5 week dark-reared cells). These differences were significant $(p=0.004)$. In summary, the results indicate that age barely affects the shape of the unitary IPSCs, whereas sensory deprivation increases their amplitude. Thus, the unitary IPSCs and the maximal IPSCs are affected in opposite directions by age and sensory experience. The changes in the frequency of mIPSCs, on the other hand, are consistent with changes in the number of synapses.

\section{Effects of age and sensory deprivation on responses evoked with minimal stimulation}

The results described above suggest that the developmental increase in the compound IPSCs is more likely to result from changes in the total number of GABAergic synapses. In turn, this could result from an increased number of GABAergic inputs and/or an increase in the average number of synaptic contacts made by each input. To explore the latter possibility, we quantified the responses of unitary GABAergic inputs using a minimal stimulation protocol (Gil, 1999). In these experiments, the recording conditions were similar to those described in Figure 5, except that TTX was not included in the bath. The stimulation 


\section{A}

Figure 6. Effects of age and sensory deprivation on layer II/III mIPSCs. $A$, Examples of current traces recorded in a 3-week-old $(3 W)$ cell, a 5-week-old $(5 W)$ cell, and a darkreared $(D R)$ cell. $N R$, Normally reared. $B$, Superimposed normalized averages of the mIPSCs recorded in all 3-weekold cells (thin line), 5-week-old cells (black thick line), and dark-reared cells ( gray thick line). For each cell, the average mIPSC was computed using the first 100 isolated events aligned by their rise time and normalized by their amplitude. Subsequently, these averages were further averaged across ages and rearing conditions. $C$, Cumulative probability distribution of the mIPSC amplitude for 3-week-old cells (thin line), 5-week-old cells (black thick line), and darkreared cells ( gray thick line). The first 300 events from each cell were used in this computation. Inset, Histograms of the amplitude distribution for all events recorded in all cells. The bin size was 5 pA. $D$, Cumulative probability distribution of the mIPSC interval. Conventions and calculations are as in C. Inset, Histograms of the interval distribution for all events recorded in all cells. The bin size was $10 \mathrm{msec}$.

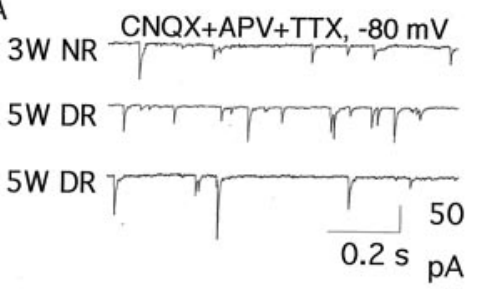

B

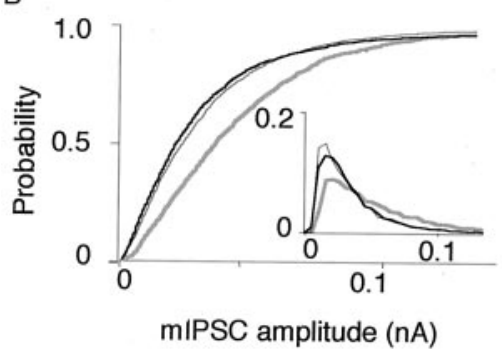

C

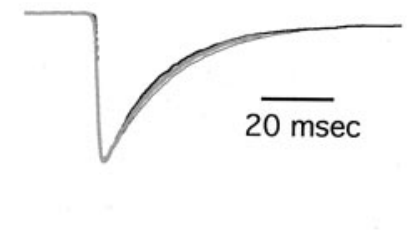

D

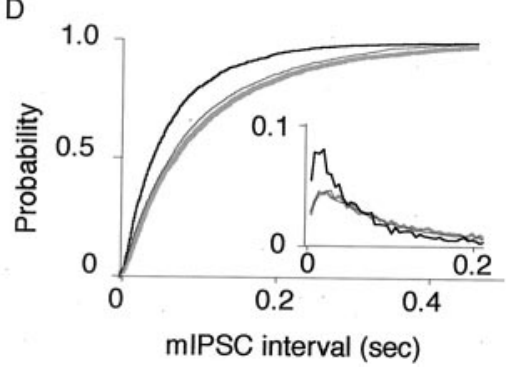

Figure 7. Effects of age and sensory deprivation on the responses evoked with minimal stimulation. All responses were recorded at $-80 \mathrm{mV}$ in the presence of $20 \mu \mathrm{M}$ CNQX and $100 \mu \mathrm{M}$ APV. $A$, Examples of responses evoked with minimal stimulation. The superimposed traces are 20 consecutive responses evoked with two stimulation intensities, $2.8 \mu \mathrm{A}($ left $)$ and $3.0 \mu \mathrm{A}$ (right). In each case, the thick traces correspond to the average of the successful responses. The amplitude histogram of the responses is displayed on the right. The noise level, calculated from the prestimulus baseline, is also plotted (in gray), but at a different scale $(2 \times) . B$, Examples of responses evoked with minimal stimulation in a 3-week-old cell $(3 \mathrm{~W}$, left $)$, a 5 -week-old cell $(5 \mathrm{~W}, \mathrm{cen}$ ter), and a 5-week-old dark-reared cell $(5 W D R$, right $)$. In each case, 20 consecutive responses are superimposed. $C$, Probability distribution of the average amplitude responses (excluding failures) evoked in 3-week-old cells (thin line), 5-week-old cells (thick line), and dark-reared cells (thick gray line). D, Relationship between the $10-90 \%$ rise time and the decay constant (top graph) and amplitude (bottom graph) for the responses evoked in 3-week-old cells $(\times)$, 5-week-old cells $(\bigcirc)$, and dark-reared cells $(\mathbf{)}$. Solid lines correspond to the best linear fit of the data. E, Normalized averaged responses recorded in all 3-week-old cells $($ thin line), 5-week-old cells (black thick line), and dark-reared cells (gray thick line). Each of the superimposed traces represents the average of all different cell responses normalized by their amplitude and aligned by their rise time.

intensity was minimized until it elicited events in an all-or-none manner. All-or-none events with similar amplitude (Fig. 6B, left) are usually presumed to originate from the activation of single axons. However, the events were often variable in amplitude (Fig. $6 \mathrm{~A})$, consistent with multiple release sites in a single input $(\mathrm{Ta}-$ mas et al., 1997; Gupta et al., 2000). To confirm that a single input was activated, we varied the stimulation intensity in small increments. At each intensity, we measured the probability of evoking a response and the average amplitude of the elicited responses (excluding failures). If multiple recruiting occurs, then one would expect that increasing the stimulus intensity will recruit more axons, thus increasing not only the probability of observing a response but also the average response amplitude. Conversely, when only one axon is recruited, increasing stimulation intensity will increase the probability of firing but should not affect the size of the evoked responses. Therefore, we considered only those cases in which changing the stimulus intensity affected the probability of evoking a response but not the average amplitude of the evoked responses (Fig. $6 A)(27 \%$ of the cells did not fulfill this criterion).

Figure 7 summarizes the results obtained with minimal stimulation in cells from 3-week-old $(n=6)$ and 5-week-old rats reared normally $(n=14)$ or reared in the dark $(n=11)$. The most dramatic effect of age and experience was on the amplitude of the evoked events (Fig. $7 B, C)$, which was significantly larger $\left(F_{(2,27)}=\right.$ $6.323 ; p=0.0046)$ in 5 week normally reared cells $(122.0 \pm 13.5$ $\mathrm{pA})$ than in 3 week normally reared cells $(53.3 \pm 7.7 \mathrm{pA})$ or in 5 week dark-reared cells $(66.4 \pm 14.8 \mathrm{pA})$. These differences in 
amplitude are not likely to be a result of differences in dendritic filtering, because there was no correlation between the rise time and the response amplitude in any of these experimental groups (Fig. 7D). The decay phase of the response (Fig. 7E), which was fitted by a single exponential (like the mIPSCs), was somewhat larger in 3 week normally reared cells $(11.17 \pm 1.49 \mathrm{msec})$ than in 5 week normally reared cells $(8.83 \pm 1.09 \mathrm{msec})$ or 5 week dark-reared cells $(8.83 \pm 1.09 \mathrm{msec})$. However, these differences were not significant $\left(F_{(2,27)}=1.182 ; p=0.3221\right)$. Finally, age and experience did not affect the rise time (10-90\% of the peak) of the minimally evoked responses $(1.58 \pm 0.19 \mathrm{msec}$ in 3 week normally reared cells, $1.46 \pm 0.165 \mathrm{msec} 5$ week normally reared cells, and $1.87 \pm 0.27 \mathrm{msec}$ in 5 week dark-reared cells; $F_{(2,27)}=$ $2.22 ; p=0.141)$. Together, these results suggest that the potency of individual GABAergic inputs onto layer II/III pyramidal cells might experience a developmental increase that can be prevented or reduced by dark rearing.

\section{DISCUSSION}

We found that inhibitory circuits continue to mature after birth in the visual cortex, and that there is a dramatic postnatal increase in the total GABAergic input converging onto layer II/III pyramidal cells. The time course of this enhancement of synaptic inhibition mirrors the decline of the critical period for experience-dependent plasticity. Like the decline of plasticity, the increase in synaptic inhibition is postponed by visual deprivation. The effects of deprivation were rapidly reversed by visual experience, but deprivation after normal experience did not affect the potency of synaptic inhibition. Thus, visual experience appears to play a permissive role and is required to trigger the normal postnatal enhancement of GABAergic inhibition. We propose that these changes result from a developmental increase in the number of release sites per individual input.

We used the maximal IPSC to assess the total GABAergic inputs onto a given cell. Because the majority of GABAergic contacts occur on the soma or on the proximal dendrites (Beaulieu and Colonnier, 1985), it is unlikely that our measurements of the IPSCs were distorted because of problems of space clamping. The absence of dendritic filtering agrees with previous findings (Ling and Benardo, 1999) and also suggests that most of the GABA synapses are close to the soma. Thus, the maximal IPSC provides a useful estimate of the total potency of the GABAergic inputs converging onto a given cell.

The developmental increase of the maximal IPSC is unlikely to result from changes in the strength of individual synapses, which is regulated in the opposite direction by age and experience. Our results indicate that the release probability declines with age and increases with sensory deprivation, which also increases the amplitude of unitary responses (mIPSCs). Thus, sensory deprivation appears to upregulate the strength of GABAergic synapses, perhaps through compensatory mechanisms similar to those described for excitatory synapses (Turrigiano et al., 1998; Murthy et al., 2001).

We propose that the developmental changes in the maximal IPSC reflect an increase in the number of GABAergic synapses. The mIPSC frequency changed in parallel with the maximal IPSC and was reduced by sensory deprivation. Although multivesicular release (Ling and Benardo, 1999; Llano et al., 2000) may also contribute, it is worth pointing out that the differences in mIPSC frequency are usually attributed to differences in the number of synapses (Salin and Prince, 1996). This interpretation is also consistent with anatomical data indicating that there is a developmental increase in the total number of GABAergic synapses (Blue and Parnavelas, 1983; Miller, 1986). Recent evidence suggests that activity-dependent release of BDNF may be one of the signals that triggers the increase in the number of GABAergic synapses (our unpublished observations).

GABAergic cells make multiple contacts with target cells (Tamas et al., 1997; Gupta et al., 2000). Using minimal stimulation, we found that the potency of putative individual GABA inputs increases during development in an experience-dependent manner. Although the interpretation of these results is somewhat limited by methodological biases (electrical stimulation might activate severed axons and preferentially recruit lower-threshold, large-caliber axons), it is worth pointing out that the same biases were applied at all ages and rearing conditions. Therefore, it seems reasonable that at least in some inputs, the number of quanta released per axonal branch increases postnatally in an experience-dependent manner. The exact contribution of these changes to the developmental increase in the maximal IPSC remains to be determined. Another open issue is the identity of the GABAergic inputs that might change during development. Inhibitory interneurons are a highly diverse group in terms of connectivity, molecular markers, and functional properties (Kawaguchi and Kubota, 1997; Parra et al., 1998; Somogyi et al., 1998; Gibson et al., 1999; Gupta et al., 2000). The magnitude of the developmental increases (twofold to threefold) in the maximal IPSC suggests that these changes might affect a large proportion of the GABAergic cells.

The strength of inhibitory circuits is considered to be important for sharpening and tuning several aspects of the cortical response to visual stimulation (Douglas, 1991; Somers and Sur, 1995). In addition, a growing body of evidence indicates that the maturation of synaptic inhibition controls the timing of the critical period for visual cortical plasticity (Kirkwood and Bear, 1994; Hensch et al., 1998; Huang et al., 1999). Visual cortical plasticity is impaired by genetic manipulations that reduce (Hensch et al., 1998) or enhance (Huang et al., 1999) the efficacy of GABAergic inhibition. Interestingly, these manipulations also impair the plasticity of excitatory connections in vitro (Huang et al., 1999; Choi et al., 2002). The exact mechanisms by which GABAergic inhibition might control plasticity are unknown. According to one view (Hensch et al., 1998), a minimum inhibitory strength is necessary to trigger the critical period for plasticity, which in turn develops with its own time course, independent of any additional change in GABAergic circuits. Alternatively, we have proposed that the synaptic modifications might require a precise range of inhibitory strengths. Below or above that range, visual cortical plasticity may not occur. A slow and progressive maturation of GABAergic inhibition then determines the precise critical period for synaptic modifications before and after which visual cortical plasticity may not occur (Rozas et al., 2001). The developmental changes in the GABAergic circuitry that we describe here fit into that scenario, although one must bear in mind that the number of GABAergic synapses is not the only factor determining the strength of inhibitory circuits. In addition to a comparable developmental time course for the increase in the IPSC and the critical period (Fagiolini et al., 1994), we found that sensory experience plays a similar role in triggering both processes. First, it prevents or delays both processes (Cynader and Mitchel, 1980). In addition, it has long been known that sensory deprivation cannot affect the critical period when preceded by normal rearing (Mower et al., 1983; Mower and Christen, 1985). Similarly, we found that the number of GABAergic synapses does not change when the ani- 
mals are sensory deprived after a period of normal rearing. In contrast, the effect of dark rearing on the maximal IPSCs was rapidly reversed by a brief exposure to light. This provides a way of testing the idea that the increase in GABAergic potency determines the end of the critical period. We predict that the critical period will terminate rapidly in dark-reared animals that are briefly exposed to light.

Together, our results show that GABAergic circuitry in the visual cortex is plastic and can be shaped by experience. Unlike the remodeling of excitatory circuitry that is primarily refinement caused by pruning of exuberant inputs, plasticity affecting inhibitory circuits appears to involve strengthening of pre-existing connections. Perhaps the two distinct modes of maturation reflect differences in functional demands of excitatory and inhibitory circuits in cortical processing. Maturation of excitatory circuitry allows increased specificity, and the mechanisms for inhibitory circuit maturation provide a powerful way to control the output of a network.

\section{REFERENCES}

Agmon A, Hollrigel G, O’Dowd DK (1996) Functional GABAergic synaptic connection in neonatal mouse barrel cortex. J Neurosci 15:4685-4695.

Barker JL, Harrison NL (1988) Outward rectification of inhibitory postsynaptic currents in cultured rat hippocampal neurones. J Neurophysiol 403:41-55.

Beaulieu C, Colonnier MA (1985) Laminar analysis of the number of round asymmetrical and flat-symmetrical synapses on spines, dendritic trunk and cell bodies in area 17 of the cat. J Comp Neurol 2:295-309.

Beaver CJ, Ji Q, Daw NW (1999) Effect of the group II metabotropic glutamate agonist, $2 R, 4 R$-APDC, varies with age, layer, and visual experience in the visual cortex. J Neurophysiol 82:86-93.

Benevento LA, Bakkum BW, Port JD, Cohen RS (1992) The effects of dark rearing on the electrophysiology of the rat visual cortex. Brain Res 572:198-207.

Benevento LA, Bakkum BW, Cohen RS (1995) Gamma-aminobutyric acid and somatostatin immunoreactivity in the visual cortex of normal and dark-reared rats. Brain Res 689:172-182.

Blue ME, Parnavelas JG (1983) The formation and maturation of synapses in the visual cortex of the rat. II. Quantitative analysis. J Neurocytol 12:697-712.

Choi SY, Morales B, Lee HK, Kirkwood A (2002) Absence of long-term depression in the visual cortex of glutamic acid decarboxylase-65 knock-out mice. J Neurosci 22:5271-5276.

Cynader M, Mitchel DE (1980) Prolonged sensitivity to monocular deprivation in dark-reared cats. J Neurophysiol 43:1026-1039.

Di Cristo G, Berardi N, Cancedda L, Pizzorusso T, Putignano E, Ratto GM, Maffei L (2001) Requirement of ERK activation for visual cortical plasticity. Science 292:2337-2340.

Douglas RJ, Martin KA (1991) A functional microcircuit for cat visual cortex. J Physiol (Lond) 440:735-769.

Dunning DD, Hoover CL, Soltesz I, Smith MA, O’Dowd DK (1999) GABA(A) receptor-mediated miniature postsynaptic currents and alpha-subunit expression in developing cortical neurons. J Neurophysiol 32:86-97.

Fagiolini M, Pizzorusso T, Berardi N, Domenici L, Maffei L (1994) Functional postnatal development of the rat primary visual cortex and the role of visual experience: dark rearing and monocular deprivation. Vision Res 34:709-720.

Gabbott PLA, Stewart MG (1987) Quantitative morphological effects of dark-rearing and light exposure on the synaptic connectivity of layer 4 in the rat visual cortex. Exp Brain Res 68:103-114.

Gibson JR, Beierlein M, Connors BW (1999) Two networks of electrically coupled inhibitory neurons in neocortex. Nature 402:75-79.

Gil Z, Connors BW, Amitai Y (1999) Efficacy of thalamocortical and intracortical synaptic connections: quanta, innervation, and reliability. Neuron 23:385-397.

Gordon BA, Kinch G, Kato N, Keele C, Lissman T, Fu LN (1997) Development of MK-801, kainate, AMPA, and muscimol, and the effect of dark rearing in rat visual cortex. J Comp Neurol 383:73-81.

Gupta A, Wang Y, Markram H (2000) Organizing principles for a diversity of GABAergic interneurons and synapses in the neocortex. Science 287:273-278.

Hensch TK, Faglioni M, Mataga N, Stryker MP, Baekkeskov S, Kash SF
(1998) Local GABA circuit control of experience-dependent plasticity in developing visual cortex. Science 282:1504-1508.

Huang JZ, Kirkwood A, Pizzorusso T, Porciatti V, Morales B, Bear MF, Maffei L, Tonegawa S (1999) BDNF regulates the maturation of inhibition and the critical period of plasticity in mouse visual cortex. Cell 98:739-755.

Hubel DH, Wiesel TN (1962) Receptive fields, binocular interaction and functional architecture in the cat's visual cortex. J Physiol (Lond) 160:106-154.

Kawaguchi Y, Kubota Y (1997) GABAergic cell subtypes and their synaptic connections in rat frontal cortex. Cereb Cortex 7:476-486.

Kirkwood A, Bear MF (1994) Hebbian synapses in visual cortex. J Neurosci 14:1634-1645.

Komatsu Y (1983) Development of cortical inhibition in kitten striate cortex investigated by a slice preparation. Brain Res Dev Brain Res 8:136-139.

Komatsu Y, Iwakiri M (1993) Long-term modification of inhibitory synaptic transmission in developing visual cortex. NeuroReport 4:907-910.

Ling DS, Benardo LS (1998) Synchronous firing of inhibitory interneurons results in saturation of fast GABA(A) IPSC magnitude but not saturation of fast inhibitory efficacy in rat neocortical pyramidal cells. Synapse 28:91-102.

Ling DS, Benardo LS (1999) Restrictions on inhibitory circuits contribute to limited recruitment of fast inhibition in rat neocortical pyramidal cells. J Neurophysiol 82:1793-1807.

Llano I, Gonzalez J, Caputo C, Lai FA, Blayney LM, Tan YP, Marty A (2000) Presynaptic calcium stores underlie large-amplitude miniature IPSCs and spontaneous calcium transients. Nat Neurosci 3:1256-1265.

Luhmann HJ, Prince DA (1991) Postnatal maturation of the GABAergic system in rat neocortex. J Neurophysiol 65:247-263.

Maffei L, Berardi N, Domenici L, Parisi V, Pizzorusso T (1992) Nerve growth factor (NGF) prevents the shift in ocular dominance distribution of visual cortical neurons in monocularly deprived rats. J Neurosci 12:4651-4662.

Miller MW (1986) Maturation of rat visual cortex. III. Postnatal morphogenesis and synaptogenesis of local circuit neurons. Brain Res Dev Brain Res 25:271-285.

Mower GD, Christen WG (1985) Role of visual experience in activating critical period in the cat visual cortex. J Neurophysiol 53:572-589.

Mower GD, Guo Y (2001) Comparison of the expression of two forms of glutamic acid decarboxylase (GAD67 and GAD65) in the visual cortex of normal and dark-reared cats. Brain Res Dev Brain Res 126:65-74.

Mower GD, Christen WG, Caplan CJ (1983) Very brief visual experience eliminates plasticity in the cat visual cortex. Science 221:178-180.

Murthy VN, Schikorski T, Stevens CF, Zhu Y (2001) Inactivity produces increases in neurotransmitter release and synapse size. Neuron 32:673-682.

Owens DF, Liu X, Kriegstein AR (1999) Changing properties of GABA(A) receptor-mediated signaling during early neocortical development. J Neurophysiol 82:570-583.

Parra P, Gulyas AI, Miles R (1998) How many subtypes of inhibitory cells in the hippocampus. Neuron 20:983-993.

Pitler TA, Alger BE (1992) Postsynaptic spike firing reduces synaptic GABA $_{\mathrm{A}}$ responses in hippocampal pyramidal cells. J Neurosci 12:4122-4132.

Rittenhouse CD, Shouval HZ, Paradiso MA, Bear MF (1999) Monocular deprivation induces homosynaptic long-term depression in visual cortex. Nature 397:347-350.

Rozas C, Frank H, Heynen A, Morales B, Bear MF, Kirkwood A (2001) Developmental inhibitory gate controls the relay of activity to the superficial layers of the visual cortex. J Neurosci 21:6791-6801.

Salin PA, Prince DA (1996) Spontaneous GABAa receptor-mediated currents in adult rat somatosensory cortex. J Neurophysiol 75:1573-1588.

Somers DCNS, Sur M (1995). An emergent model of orientation selectivity in cat visual cortical simple cells. J Neurosci 15:5448-5465.

Somogyi P, Tamas G, Lujan R, Buhl EH (1998) Salient features of synaptic organisation in the cerebral cortex. Brain Res Brain Res Rev 26:113-135.

Tamas G, Buhl EH, Somogyi P (1997) Fast IPSPs elicited via multiple synaptic release sites by different types of GABAergic neurone in the cat visual cortex. J Physiol (Lond) 500:715-738.

Turrigiano GG, Leslie KR, Desai NS, Rutherford LC, Nelson SB (1998) Activity-dependent scaling of quantal amplitude in neocortical neurons. Nature 391:892-896.

Wilson RI, Nicoll RA (2001) Endogenous cannabinoids mediate retrograde signalling at hippocampal synapses. Nature 410:588-592.

Winfield DA (1983) The postnatal development of synapses in the different laminae of the visual cortex in the normal kitten and in kittens with eyelid suture. Brain Res Dev Brain Res 9:155-169. 